\title{
Neonatal screening for cystic fibrosis in Wales and the West Midlands: clinical assessment after five years of screening
}

\author{
S Chatfield, G Owen, H C Ryley, J Williams, M Alfaham, M C Goodchild, P Weller
}

\begin{abstract}
Screening of the newborn for cystic fibrosis by measurement of immunoreactive trypsin has been undertaken on alternate weeks in Wales and the West Midlands for five years since 1985 to evaluate the possible clinical benefits of early diagnosis. Patients detected by screening and those diagnosed by clinical symptoms alone were assessed annually for differences in clinical, anthropometric, and biochemical variables. Fifty eight infants not considered to be at risk of cystic fibrosis (they did not present with meconium ileus and do not have a sibling with cystic fibrosis) have been detected by screening and they have been compared with 44 children who were diagnosed clinically. This latter group includes nine children whose screening was negative but who were recognised subsequently to have cystic fibrosis. The mean age at diagnosis of the screened group was significantly lower than that of the group diagnosed clinically. Excluding admissions for diagnostic tests for cystic fibrosis, the screened group spent a significantly shorter time in hospital during the first year of life. The results of all other comparisons made between the screened group and those diagnosed clinically were similar up to the age of 4 years.
\end{abstract}

Screening for cystic fibrosis by measurement of the concentration of immunoreactive trypsin in the blood has now been done for 10 years, since Crossley et al first described the phenomenon of raised immunoreactive trypsin values in heelprick blood samples from neonates with cystic fibrosis. ${ }^{12}$ Reasons for screening for cystic fibrosis (or any other disease) rest upon the principles of Wilson and Jungner. ${ }^{3}$ In essence, the disease should have a latent or early symptomatic state that can be modified by agreed treatment. While the former is usually true for cystic fibrosis, there is at present no agreed treatment protocol. ${ }^{4}$

Several groups have attempted to substantiate the case for screening for cystic fibrosis by making longitudinal comparisons of screened patients and those recognised in previous years by clinical criteria. ${ }^{5-8}$ Other reports have concerned the better clinical state of children with cystic fibrosis who were diagnosed during the first year of life-earlier than contemporaries ${ }^{9}$ or siblings. ${ }^{10}$ All these studies have been open to the criticism that like has not been compared with like. ${ }^{11}$ The diagnostic delay that occurs in cystic fibrosis can, however, be improved by screening, ${ }^{12}$ and the identification of nutritional deficiencies by screening in some infants with cystic fibrosis before the age of 2 months gives further support for screening and early diagnosis. ${ }^{13}$

To find out the possible clinical benefits of early diagnosis after screening, a large comparative study of screening for cystic fibrosis by measurement of immunoreactive trypsin on routinely collected blood spots (Guthrie card specimens at 5-10 days of age) was set up in Wales and the West Midlands in January 1985, funded by the Cystic Fibrosis Research Trust. During the five year period 227183 neonates were screened for cystic fibrosis (table 1 ) and an estimated 246959 were not screened (table 2). In this paper we make a clinical comparison between screened and clinically diagnosed patients from data produced to December 1989.

\section{Patients and methods}

IDENTIFICATION OF PATIENTS

The protocol of the trial has been described previously. ${ }^{11}$ Infants born in Wales (population 2.7 million) and the West Midlands (population $4 \cdot 1$ million) were tested on alternate weeks, thus identifying two groups in each area: screened and unscreened. Results for patients in both areas are considered together.

Specimens from neonates collected in central Birmingham were sent to a separate local screening laboratory and no children born in the central Birmingham area are included in this

Table 1 Details of infants screened 1985-9. Total number of specimens received: 227183

\begin{tabular}{|c|c|}
\hline & $\begin{array}{l}\text { No of } \\
\text { specimens }\end{array}$ \\
\hline $\begin{array}{l}\text { Positive first immunoreactive trypsin test } \\
\text { Positive second immunoreactive trypsin test } \\
\text { False positive tests (sweat test negative) } \\
\text { Infants identified as having cystic fibrosis } \\
\text { (sweat test positive): } \\
\text { Not at risk } \\
\text { With meconium ileus } \\
\text { With elder sibling with cystic fibrosis } \\
\text { Specimens giving false negative diagnoses for } \\
\text { cystic fibrosis: } \\
\text { Not at risk } \\
\text { With meconium ileus } \\
\text { With elder sibling with cystic fibrosis }\end{array}$ & $\begin{array}{l}947(0 \cdot 42 \%) \\
98 \\
33\end{array}$ \\
\hline $\begin{array}{l}\text { Total No of cases } \\
\text { by screening }\end{array}$ & $78(1 / 2912)$ \\
\hline
\end{tabular}

Table 2 Details of infants who were not screened 1985-9

\begin{tabular}{lc}
\hline Estimated No of unscreened infants & 246959 \\
Total No of unscreened infants known to have & $66(1 / 3741)$ \\
cystic fibrosis: & 35 \\
Not at risk & 19 \\
With meconium ileus & 12 \\
With elder sibling with cystic fibrosis & \\
\hline
\end{tabular}


trial. As the Birmingham Children's Hospital is in central Birmingham, and most infants born in the West Midlands with meconium ileus are referred there, there is an abnormally high incidence of children with meconium ileus in the unscreened group of patients. This anomaly does not, however, affect the random allocation of children who were not at risk into the 'screened' and 'clinical' groups at the annual assessment.

Permission for the trial was obtained from the ethics committee of each area health authority. A change in attitude to the protocol in one district of the West Midlands led to stopping the screening early in the West Midlands (in October 1989), though screening continued in Wales until December 1989. Patients with cystic fibrosis born in the West Midlands between October and December 1989 are included in the unscreened group. We feel that three months out of a five year period is unlikely to have a significant effect on the random allocation of children into screened and unscreened groups.

Immunoreactive trypsin was measured at 5-10 days by radioimmunoassay using the Behring kit (Hoechst Pharmaceuticals). ${ }^{11}$ Subjects with a positive immunoreactive trypsin result (over $900 \mathrm{ng} / \mathrm{ml}$ ) were retested at 6 to 8 weeks. As immunoreactive trypsin in infants with cystic fibrosis falls with time, ${ }^{11}$ the upper limit of normal for the second test was taken as $600 \mathrm{ng} / \mathrm{ml}$ and if this was exceeded the child was referred by the general practitioner to the local paediatrician for sweat testing by pilocarpine iontophoresis. ${ }^{14}$ No follow up was arranged for infants with only a single positive immunoreactive trypsin value, or for those with two positive results followed by a normal sweat test. Routine treatment included chest physiotherapy, antibiotics according to an agreed protocol, pancreatic enzymes according to clinical need, and vitamin supplementation.

\section{FOLLOW UP OF PATIENTS}

Children were assessed on entry to the trial, and various groups were identified based on mode of presentation.

Yearly comparisons were made between infants identified after positive immunoreactive trypsin screening and those diagnosed clinically (the latter group includes those with a false negative immunoreactive trypsin result who were later found to have cystic fibrosis). Infants with meconium ileus and siblings of known patients with cystic fibrosis were considered to be 'at risk' of cystic fibrosis and their results have been excluded from the yearly comparisons.

Each child was reviewed annually by one of us. Detailed information was obtained about the child's health during the previous year including admissions to hospital for illnesses that could be related to cystic fibrosis. A full clinical examination and chest radiograph were done, and height, weight, and skinfold thickness were measured. A blood sample was obtained for various indices: haematological (full blood count, clotting picture, ferritin and folate concentra- tions); biochemical (plasma electrolyte concentrations, liver function tests, and concentrations of fat soluble vitamins, cholesterol, fatty acids, trace elements, uric acid, and immunoreactive trypsin); immunological (concentrations of immunoglobulins); and for virus titres.

Between annual assessments children were followed up by their local paediatricians.

\section{STATISTICAL ANALYSIS}

The distribution of many of the variables was skewed, and consequently comparison of the data is by the non-parametric Mann-Whitney U test.

\section{Results}

DETECTION OF INFANTS WITH CYSTIC FIBROSIS

Between January 1985 and December 1989, 227183 specimens collected in Wales and the West Midlands were routinely screened, and 65 infants with cystic fibrosis were detected after positive screening, of whom 58 were considered not to be 'at risk' (table 1). In addition, 13 specimens from infants subsequently proved to have cystic fibrosis were negative by immunoreactive trypsin screening. Thus there is a total of 78 infants known to have cystic fibrosis in this group giving an incidence of 1/2912. During the same period within the same area an estimated 246959 specimens were not screened and 66 infants with cystic fibrosis were detected, although only 35 were not 'at risk' (table 2 ). The

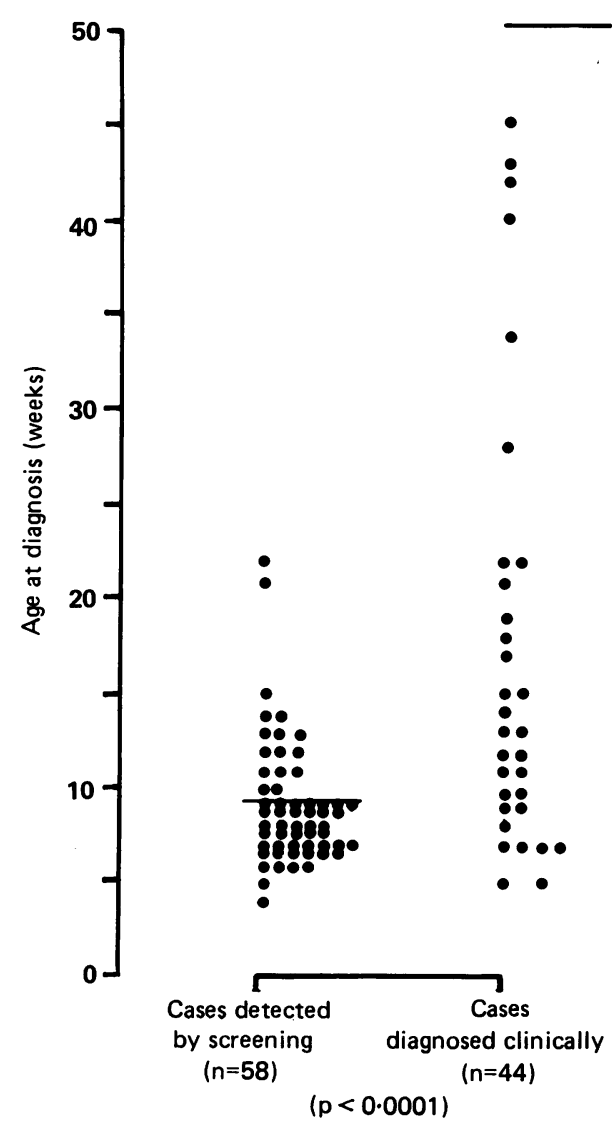

Ages of children at diagnosis; the horizontal bars represent the means. The ages (weeks) of children over the age of 1 year at diagnosis were $71,80,87,95,116,119,123,150,151$, 156,213 , and 230 . 
Table 3 Symptoms in infants not considered to be at risk of cystic fibrosis but detected by screening compared with those detected clinically. Figures are expressed as numbers (\%)

\begin{tabular}{lcc}
\hline & $\begin{array}{l}\text { Infants detected } \\
\text { by screening } \\
(n=58)\end{array}$ & $\begin{array}{l}\text { Infants detected } \\
\text { clinically } \\
(n=44)\end{array}$ \\
\hline Respiratory symptoms only & $10(17)$ & $4(9)$ \\
Gastrointestinal symptoms only & $9(16)$ & $7(16)$ \\
Respiratory and gastrointestinal symptoms & $17(29)$ & $33(75)$ \\
Failure to thrive only & $6(10)$ & 0 \\
Asymptomatic & $16(28)$ & 0 \\
\hline
\end{tabular}

difference between the total numbers of patients with cystic fibrosis in each group (78 and 66) was not significant $\left(\chi^{2}=2 \cdot 27, \mathrm{df}=1,0 \cdot 2>\mathrm{p}<0 \cdot 1\right)$, but there was a significant difference between the numbers of infants with cystic fibrosis not 'at risk' (58 and 35$)\left(\chi^{2}=7 \cdot 78, \mathrm{df}=1, \mathrm{p}<0 \cdot 01\right)$.

\section{ASSESSMENT AT ENTRY}

Information at entry into the trial is available on all patients. Infants presenting with meconium ileus and siblings of patients known to have cystic fibrosis have been excluded. Nine children with false negative screening results are included in the group that was diagnosed clinically.

The mean (SD) age at diagnosis of the screened patients $(9 \cdot 1(3 \cdot 1)$ weeks) was significantly lower than that of those clinically diagnosed (50.7 (60.5) weeks) ( $p<0.001$, figure).

Symptoms at diagnosis are shown in table 3. Less than one third of the screened group was asymptomatic at the time of diagnosis, while the others had symptoms referrable to the respiratory or gastrointestinal systems, or both. Three quarters of the group diagnosed clinically had both respiratory and gastrointestinal symptoms at the time of diagnosis.

Information about hospital admissions with symptoms attributable to cystic fibrosis before the time of diagnosis was available in most cases. In the screened group, 11 of 55 patients had had one such admission, and in only one case was the diagnosis of cystic fibrosis being considered before notification of the positive screening test result. Twenty six of 43 children clinically diagnosed had had at least one such admission.

\section{ANNUAL ASSESSMENT}

The number of children assessed in each of the first four years of life is shown in table 4 . Clinical comparisons were made between infants detected by screening who had no risk factors for cystic fibrosis and children who were diagnosed clinically.

There were no significant differences in weight and height SD scores between the two groups at any age, though there was a tendency for the scores to improve in both groups from the ages of 1-3 years (table 5).

Shwachman scores (score for overall well being; points deducted for adverse features;

Table 4 No of infants assessed at ages $1-4$ years

\begin{tabular}{lllll}
\hline & \multicolumn{4}{l}{ Age (years) } \\
\cline { 2 - 5 } & 1 & 2 & 3 & 4 \\
\hline $\begin{array}{l}\text { No detected by screening } \\
\text { No detected clinically }\end{array}$ & 44 & 33 & 23 & 12 \\
\hline
\end{tabular}

Table 5 Mean (SD) weight and height SD scores for those patients detected by screening and those diagnosed clinically at ages 1-4 years. There was no significant difference at any age

\begin{tabular}{lll}
\hline & $\begin{array}{l}\text { Patients } \\
\text { detected } \\
\text { by screening }\end{array}$ & $\begin{array}{l}\text { Patients } \\
\text { detected } \\
\text { clinically }\end{array}$ \\
\hline $\begin{array}{l}\text { Weight SD scores: } \\
\text { 1 year }\end{array}$ & $-0.62(1)$ & $-0.54(0.9)$ \\
2 years & $-0.38(0 \cdot 8)$ & $-0.47(0.9)$ \\
3 years & $-0.12(1)$ & $-0.4(0.4)$ \\
4 years & $-0.4(1 \cdot 2)$ & $-0.15(0.4)$ \\
Height SD scores: & $-0.67(1 \cdot 1)$ & $-0.55(1)$ \\
1 year & $-0.47(0.9)$ & $-0.77(0.9)$ \\
2 years & $+0.07(1)$ & $-0.35(0.9)$ \\
3 years & $-0.09(1 \cdot 2)$ & $-0.39(0.9)$ \\
\hline years & & \\
\hline
\end{tabular}

maximum score 100$)^{15}$ and Chrispin-Norman scores (chest radiography only; points allocated for adverse features to a total of 38$)^{16}$ were similar at the ages of 1 to 4 years. The mean Shwachman scores were between 85 and 90 in both groups and the mean Chrispin-Norman scores between 4 and 7 at all ages.

There were no significant differences between the groups in the results of any of the laboratory tests.

During the first year of life only, the mean (SD) number of hospital admissions (screened 1.3 (1.9), clinical $3.2(2.7)$ admissions) and length of time spent in hospital with illness associated with cystic fibrosis (screened $19 \cdot 2$ (42.9) days, clinical $27(22 \cdot 7)$ days) were significantly greater in the group diagnosed clinically $(\mathrm{p}<0.01)$. Admissions for diagnosis and initiation of treatment have been excluded from these figures.

DEATHS

There have been four deaths so far, all in the group diagnosed clinically. One infant who had presented with meconium ileus and had a positive sweat test, died at the age of 10 weeks of sudden infant death syndrome. Another child with a chest infection who had been confirmed to have cystic fibrosis by two positive sweat tests died at the age of 11 weeks. A third infant with extensive chest infection and a positive sweat test also died at the age of 11 weeks, despite ventilation. A fourth child, who had been treated for asthma, died suddenly at the age of 22 months; at necropsy cardiomyopathy and features of cystic fibrosis were found. No sweat test had been done though it transpired later that this child had had two first cousins with cystic fibrosis. A retrospective immunoreactive trypsin analysis of the neonatal blood sample of the third and fourth patients showed positive results in both cases.

\section{Discussion}

This large screening study carried out in Wales and the West Midlands over a five year period has shown that neonatal screening for cystic fibrosis could be integrated into the existing national screening programme. Values for specificity and reliability of the immunoreactive trypsin test were similar to those found previously. ${ }^{17}$

The incidence of cystic fibrosis in the screened 
population (1/2912) was slightly lower than previously reported, ${ }^{18}$ but this figure may have been affected by the exclusion of children born in the West Midlands who had meconium ileus. When the incidence is calculated for Welsh children alone (where this anomaly does not occur) the figure is $1 / 2671$. It is possible that this incidence will increase if more children with negative immunoreactive trypsin tests are found to have cystic fibrosis.

The false negative incidence in this study, at $12.8 \%$, is higher than in some previous reports, ${ }^{17} 19$ but lower than in another. ${ }^{20}$ The incidence would not be reduced by lowering the cut off value for the initial immunoreactive trypsin test. In our opinion the immunoreactive trypsin test is not as specific as previously reported ${ }^{1}$ and it is important to stress the need for sweat testing where cystic fibrosis is suspected clinically.

The incidence of false positive results in the study is similar to that found by others. ${ }^{5}$ The period between the initial positive immunoreactive trypsin test and the result of the sweat test is distressing to families and it is essential to keep this time to a minimum. A survey of some of the families who took part in this study showed that most parents supported screening, whether their child had been screened or clinically diagnosed. ${ }^{21}$ All families experienced some change in their feelings for their child after learning the diagnosis, however, and 'several families emphasised the importance of minimal delay between the initial mention of the possibility of cystic fibrosis on immunoreactive trypsin testing and the confirmation (or otherwise) of the diagnosis'.

The identification of the cystic fibrosis gene and major deletion ( $\delta$ F508) found in about 70\% of cystic fibrosis chromosomes of northern European origin could permit rapid diagnosis of about half the patients who develop cystic fibrosis without a previous family history, who are homozygous for this deletion. ${ }^{22}$ The obligatory false negative rate of the other half implies that neonatal screening for cystic fibrosis by DNA analysis is not appropriate at present.

During the five years of the study 144 children with cystic fibrosis have entered the trial. Of these, 78 were screened and 66 not screened. When children 'at risk' of cystic fibrosis are excluded there are significantly fewer children in the unscreened group (35 compared with 58 screened). This indicates a possible cohort of children in the unscreened population who have cystic fibrosis who have not yet been diagnosed, and lends support to the theory of Warwick that a substantial number of patients with cystic fibrosis remain undiagnosed, some for years, and some even at necropsy. ${ }^{23}$

Analysis of the 'not at risk' groups (screened and clinically diagnosed) permits a comparison of early and late diagnoses and an assessment of the effects of screening. A significant difference is found for age at diagnosis (figure). The SD is wide for the clinical group with $27 \%$ over the age of 1 year, the oldest being 4.5 years, which is similar to results reported previously for unscreened patients. ${ }^{12}$
Most children who are detected by screening had symptoms attributable to cystic fibrosis at the time of diagnosis and several had already been admitted to hospital. Cystic fibrosis was not considered in some of the clinically diagnosed group until they had had more than one admission to hospital; this has also been reported by Wilcken et al. ${ }^{12}$

Although the screened patients were diagnosed and treated earlier, we were unable to show any clinical differences between the two groups of patients at the ages of 1 to 4 years. Previous studies have shown differences among older children and it is possible the patient groups will diverge later. ${ }^{78}$ The present tests may be too insensitive to detect any differences that are present. Our patients are too young to do lung function tests; when this is possible these tests may allow finer discrimination of differences between those who were screened and those who were diagnosed clinically.

We did find that the screened children had significantly fewer admissions to, and spent less time in, hospital in the first year of life for problems related to cystic fibrosis, even when admissions for diagnosis and initiation of treatment were excluded. This supports previous findings of reduced morbidity in the early years of life of children with cystic fibrosis who were detected by screening. ${ }^{56}$ It may introduce an element of cost effectiveness into screening for cystic fibrosis, but to assess this accurately it would be necessary to know the cost of treatment for patients whose lives were extended by early identification and treatment, if this proved to be the case.

All four deaths occurred in unscreened patients. While this illustrates that infants with cystic fibrosis are vulnerable at a young age, it does not allow any deductions to be made about the effect of screening, as three of the infants died at about the mean time of the recognition of cystic fibrosis by our screening programmethat is, at 2-3 months.

Whatever the effect of earlier diagnosis on the clinical state of children with cystic fibrosis there is little doubt that genetic counselling should be made available to affected families as soon as possible, ${ }^{24}$ to enable them to make considered decisions on their future family plans. $^{25}$

Although the screening programme ended in December 1989 we plan to follow up the identified cohorts of patients for many years. This should provide the answer to the question of whether early diagnosis and treatment are beneficial to children with cystic fibrosis.

We thank the Directors of the Regional Neonatal Screening Units (Dr RA Carter, West Midlands, and Dr D Bradley, Wales); Dr S Chapman, for reviewing radiographs from the West Midlands, and Professor JA Dodge for helpful discussions. We are grateful to our paediatric colleagues in Wales and the West Midlands for assistance and collaboration. The survey was funded by the Cystic Fibrosis Research Trust, which also
supported Dr Chatfield, Dr Owen, Dr Williams, and Dr Alfaham.

1 Crossley JR, Elliot RB, Smith PA. Dried blood-spot screening for cystic fibrosis in the newborn. Lancet 1979;i:472-4. 
RB. Neonatal screening for cystic fibrosis, using immunoreactive trypsin assay in dried blood spots. Clin Chim Acta 1981;113:111-21.

3 Wilson JMG, Jungner G. Principles and practice of screening for disease. Geneva: WHO, 1968

4 Goodchild MC, Dodge JA. Cystic fibrosis: manual of diagnosis and management. London: Baillière Tindall, 1985.

5 Bowling F, Cleghorn G, Chester A, et al. Neonatal screening for cystic fibrosis. Arch Dis Child 1988;63:196-8.

6 Wilcken B, Chalmers G. Reduced morbidity in patients with cystic fibrosis detected by neonatal screening. Lancet 1985; ii:1319-21.

7 Dankert-Roelse JE, Meerman GJ, Martijn A, Ten Kate LP, Knol K. Survival and clinical outcome in patients with cystic fibrosis, with or without neonatal screening. cystic fibrosis, with or

8 Mastella G, Barlocco EG, Antonacci B, et al. Is neonatal screening for cystic fibrosis advantageous? The answer of a wide 15 year follow up study. Proceedings de Conference Internationale Mucoviscidose. October 5-6, 1988. Caen: University of Caen, 1988:127-43.

9 Shwachman H, Redmond A, Khaw KT. Studies in cystic fibrosis: report of 130 patients diagnosed under 3 months of age over a 20-year period. Pediatrics 1970;46:335-43.

10 Orenstein DM, Boat TF, Stern RC, et al. The effect of early diagnosis and treatment in cystic fibrosis. A seven-year study of 16 sibling pairs. Am $\mathcal{J}$ Dis Child 1977;131:973-5.

11 Ryley HC Deam SM, Williams J, et al. Neonatal screening for cystic fibrosis in Wales and the West Midlands: I. Evaluation of immunoreactive trypsin test. $\mathcal{F}$ Clin Pathol 1988;41:726-9.

12 Wilcken B, Towns SJ, Mellis CM. Diagnostic delay in cystic fibrosis: lessons from newborn screening. Arch Dis Child 1983;58:863-6.

13 Reardon MC, Hammond KB, Accurso FJ, et al. Nutritional deficits exist before 2 months of age in some infants with cystic fibrosis identified by screening tests. $\mathcal{F}$ Pediatr 1984;105:271-4.

14 Gibson LE, Cooke RE. A test for concentration of electrolytes in sweat in cystic fibrosis of the pancreas, utilizing pilocarpine by iontophoresis. Pediatrics 1959;23:545-9.

15 Shwachman H, Kulczycki LL. Long term study of 105 patients with cystic fibrosis. Am $\mathcal{F}$ Dis Child 1958;96:6-15.

16 Chrispin AR, Norman AP. The systematic evaluation of the chest radiograph in cystic fibrosis. Pediatr Radiol 1974;2: 101-6.

17 Wilcken B, Brown ARD, Urwin R, Brown DA. Cystic fibrosis screening by dried blood spot trypsin assay: results in 75000 newborn infants. $\mathcal{F}$ Pediatr 1983;102:383-7.

18 BPA Working Party on Cystic Fibrosis. Cystic fibrosis in the United Kingdom 1977-1985: an improving picture. BMF United Kingdom 1977-

19 Heeley AF, Heeley ME, King DN, Kuzemko JA, Walsh MP. Screening for cystic fibrosis by dried blood spot trypsin assay. Arch Dis Child 1982;57:18-21.

20 Roberts G, Stanfield M, Black A, Redmond A. Screening fo cystic fibrosis: a four year regional experience. Arch Dis Child 1988;63:1438-43.

21 Al-Jader LN, Goodchild MC, Ryley HC, Harper PS Attitudes of parents of cystic fibrosis children towards neonatal screening and antenatal diagnosis. Clin Genet 1990 (in press).

22 Kerem B-S, Rommens JM, Buchanan JA, et al. Identification of the cystic fibrosis gene: genetic analysis. Science 1989; 245:1073-80.

23 Warwick WJ. Undiagnosed patients with cystic fibrosis. f Chronic Dis 1980;33:685-96.

24 Dodge JA. Implications of the new genetics for screening for cystic fibrosis. Lancet 1988;ii:672-4.

25 Dankert-Roelse JE, Meerman GJ Knol K, Ten Kate LP. Effect of screening for cystic fibrosis on the influence of Effect of screening for cystic fibrosis on the
genetic counselling. Clin Genet 1987;32:271-5. 